\title{
Structural Study of Cretaceous Formations for Sufaiya Area Northwest Iraq
}

Ahmed Ibrahim Saleh Al-Naemi, Dr. Torhan Medhhir Hasan Almufti

General Secretary of the Provinces of Iraq, NOC, Geological Department

\section{Introduction}

The seismic surveys by the Iraqi petroleum Company in 1956 for the Sufaiya area showed the existence of a geophysical phenomenon extending northwest-southeast, followed several seismic surveys in that area which confirmed the presence of a geological structure in that area. Then, other seismic surveys were carried out to clarify the structural side of the field includes the survey of the Bulgarian Techno export Company 1977.

The exploration well Sufaiya -1 was drilled in 1973 and the drilling reached the depth 3504 meters from Rotary Table Kelly Bushing. The oil appeared in the Gir Bir, Mushorah and Shiranish Formations, produced gas and condensate in the Karra Chine formation. In the light of this promising information and information obtained from the seismic surveys and drilling wells in the structure. The drilling wells continued in this structure until to reach the number of wells in the Sfaiya area 47 wells, including 5 wells penetrating the Gir Bir reservoir completely, which is Sfaiya - 1, 2, 4, 12 and 29.

\section{Surface geology of the study area}

Sufaiya structure area is characterized by a wavy surface with multiple hills. Sufaiya structure is considered from the structures that appears on the surface, where the Fatha Formation is the exposed part of the surface, while the Injana and Mukdadia Formations were exposed and precipitate in the surrounding area.

\section{Location of study area}

The Sfaiya field is located northwest of Iraq, 100 kilometers north-west of Mosul and $15 \mathrm{~km}$ northeast of the Rabia town, Figure (1). Structurally, The Sufaiya field is located in the unstable shelf and within the foothill zone in Butmah-Mosul belt according to the structural map of Iraq prepared by the General Establishment of Geological Survey and Mining / 1996 in Jassim and Goff, 2006. 


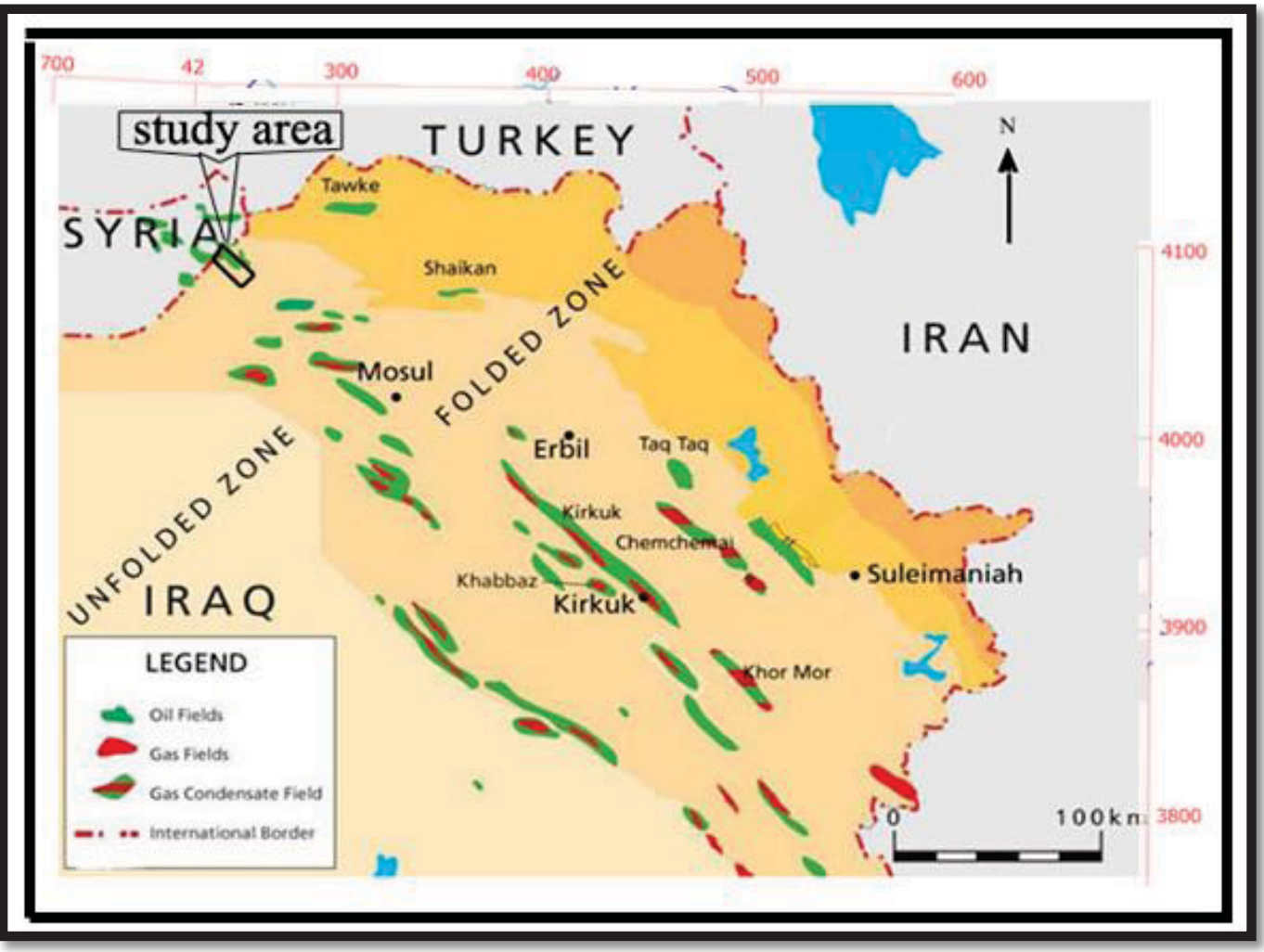

Fig. (1) The location map of study area.

\section{$\underline{\text { Previous studies }}$}

According to previous studies, it is possible to say that there is a difference in the views of the structural body of the Sufaiya Field, which mostly indicated that the Sfaiya field is a complex anticline fold for the effect of a number of tectonic movements during different geological times, and the geographical location of the Sfaiya structure and surround structures made it vulnerable to the influence of the tectonic movements of Zagros and Turos, creating a kind of complex and unclear structural on the one hand, and on the other, making the fold extended horizontally at the expense of vertical extent, figure (2). 


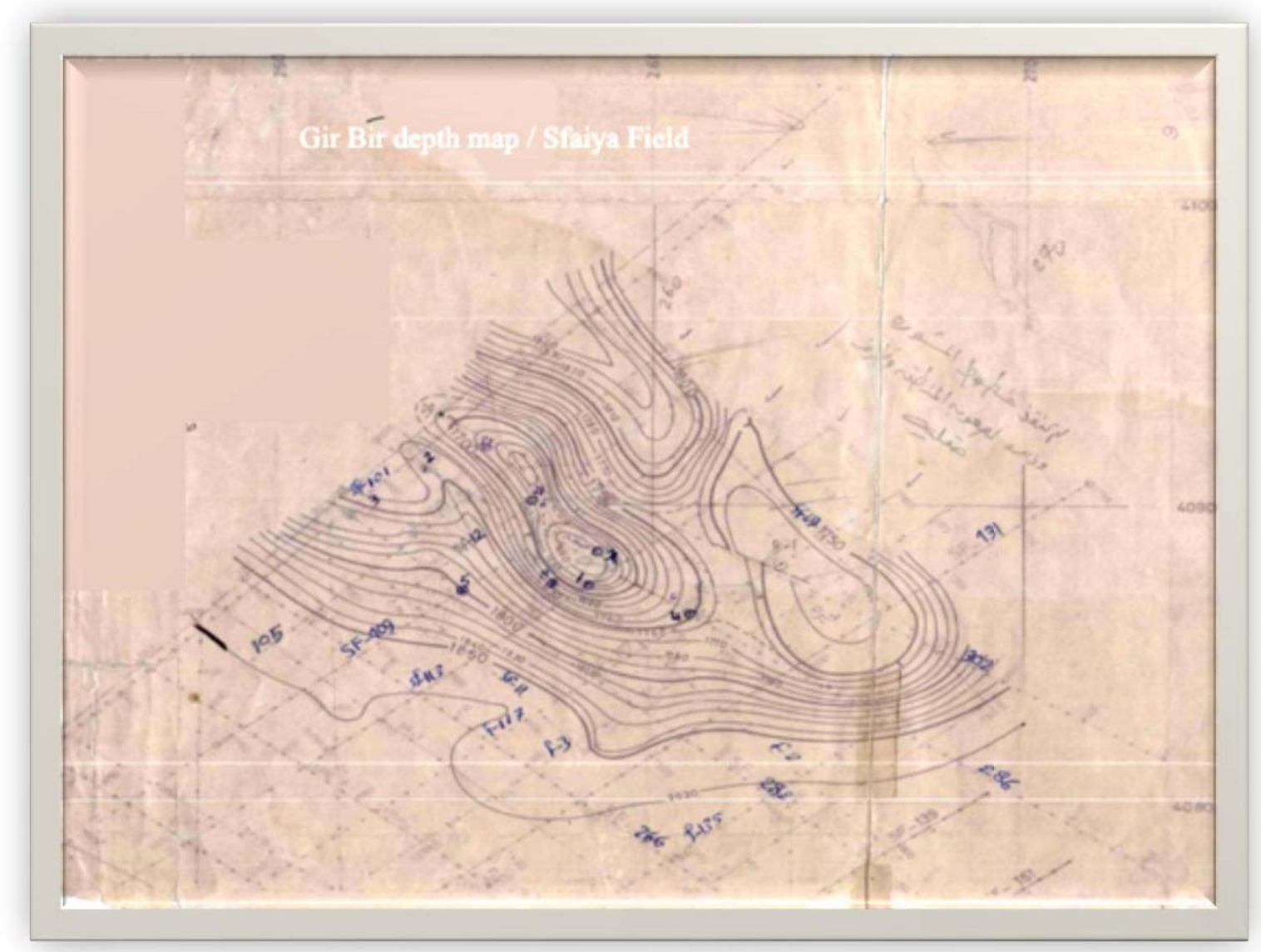

Fig. (2) Gir Bir Formation depth map of Sufaiya Field" reference (EOC, 1980: in Arabic)"

\section{Objective of the study}

Updating the structural maps of the cretaceous reservoirs and determining the types of faults affecting them and their trends, in addition to knowledge of the structural relationship between Sufaiya Field and the Souedih Field.

\section{stratigraphy of study area}

The stratigraphy of cretaceous age in Iraq and the Arabian plate represent TectonostratigraphicMegasequences cycles (Sherland et al, 2001)

AP9 - Middle Turonian - Early Paleocen

It can be said that the AP8 phase is characterized by several local uplift during the sedimentation period and the decline in the global sea level, which corresponds to existing in northwestern Iraq (north of the Arabian plate), which varies in tectonic and stratigraphy phases, which led to the loss of most of the lower cretaceous formations.

AP8 - Early Tithonian - Middle Turonian 
The AP9 phase in northwestern Iraq, specifically in the Sufaiya area, that is different from the other Arabian plate and the eastern parts of Iraq, which topography of the basin in this part is heterogeneous, and that began uplift from Sufaiya area toward Tell Hajar and Ain Zalah area.

The sequence stratigraphy of the Upper cretaceous in Sfaiya field is represented by the following sedimentary cycles:

1. Early Cenomanian-Early Turonian cycle, which is of reservoir importance and includes the Gir Bir Formation that equivalent for the Mishrif and Rumaila Formations in southern Iraq.

2. Late Turonian - Early Campianian cycle. The depositions of this cycles are completely missing in a Sufaiya Field, represent conglomerate form due to tectonic instability in the region, compared to eastern and central Iraq, with the Mushorah formation.

3. The late Campanian -Maastrichtian cycle. Represented by Shiranish Formation inter fingering with Aqra Formation.

\section{Structure contour map on top of Shiranish Formation}

After drawing and updating the structure contour map on top of Shiranish formation, we can separate the so-called Sfaiya structure into two parts. The first consists of a Sfaiya structure containing 26 wells, which is an asymmetrical anticline fold. Its southwestern flank is more inclined than its northeastern flank, and the axis direction northwestern-southeastern, toward Zagros, with dimensions of $(11 * 4.5 \mathrm{~km})$ at the top of Shiranish formation. The second consists of the Souedih structure (the area of southeastern plunge of the Souedih Field) containing 17 wells, which is an asymmetrical anticline fold, whose southwestern flank is more inclined than its northeastern flank and the axis direction (northwest-southeast) with dimensions $(3 * 4 \mathrm{~km})$ At the top of the Shiranish formation, which lies in the Iraqi border area, the narrow syncline separates between the Souedih and Sufaiya structures, and containing 4 wells, figure (3). 


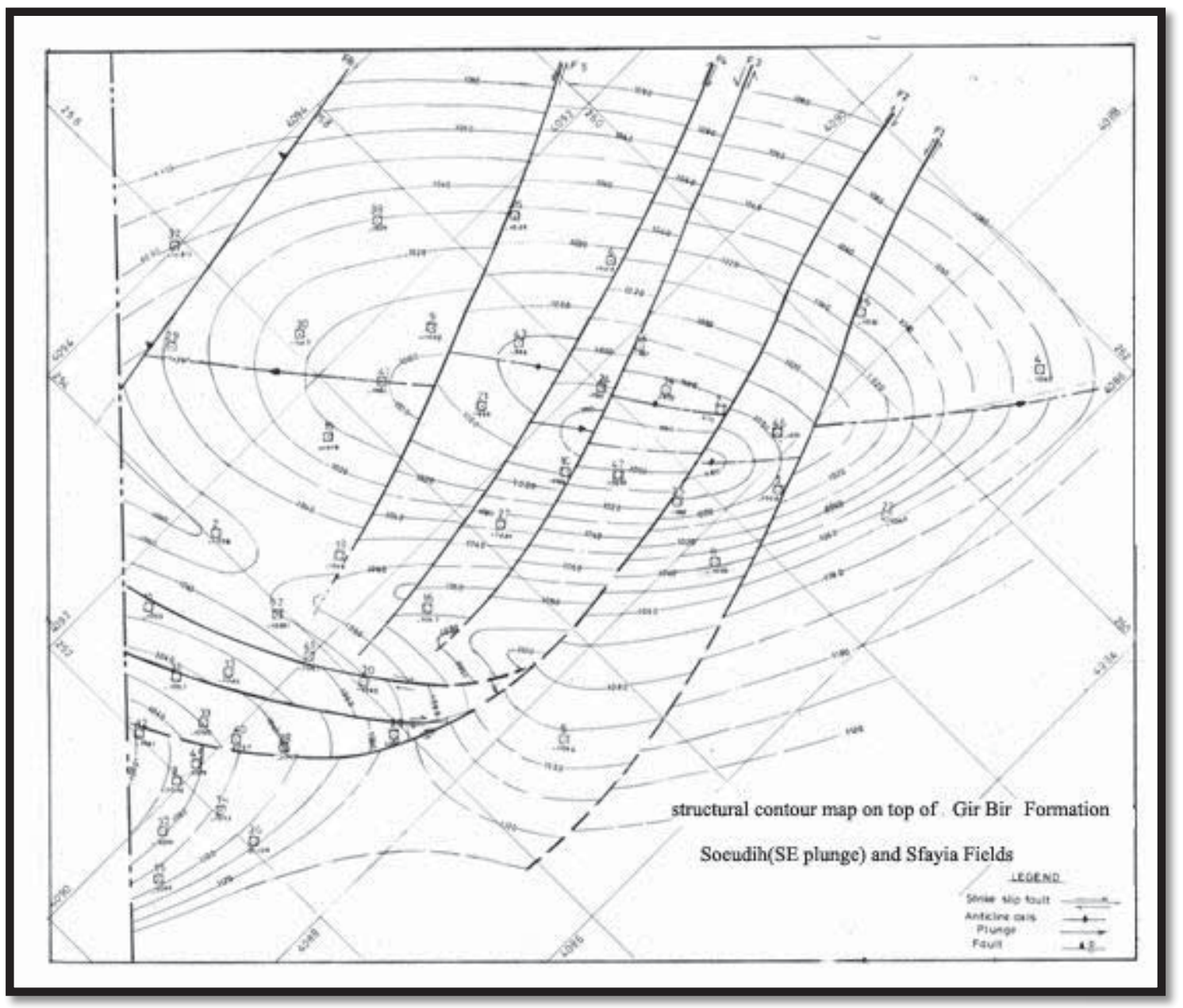

Fig. (3) Structure contour map on top of Shiranish Formation

\section{Structure contour map on top of Gir Bir Formation:}

After drawing and updating the structure contour map on top of Gir Bir Formation, , we can separate the so-called Sfaiya structure into two parts: The first consists of a Sfaiya structure, which is an asymmetrical anticline fold. Its southwestern flank (about 6 degree) is more inclined than its northeastern flank (about 2.5 degrees), and the axis direction northwestern-southeastern, toward Zagros, with dimensions of $(11 * 4.5 \mathrm{~km})$ at the top of Gir Bir formation. The second consists of the Souedih structure (the area of southeastern plunge of the Souedih Field), which is an asymmetrical anticline fold, whose southwestern flank(about 6 degrees) is more inclined than its northeastern flank(about 3 degrees) and the axis direction (northwest-southeast) with dimensions $(3 * 4 \mathrm{~km})$ At the top of the Gir Bir Formation, which lies in the Iraqi border area, the narrow syncline separates between the Souedih and Sufaiya structures, and containing 4 wells, figure(4). 


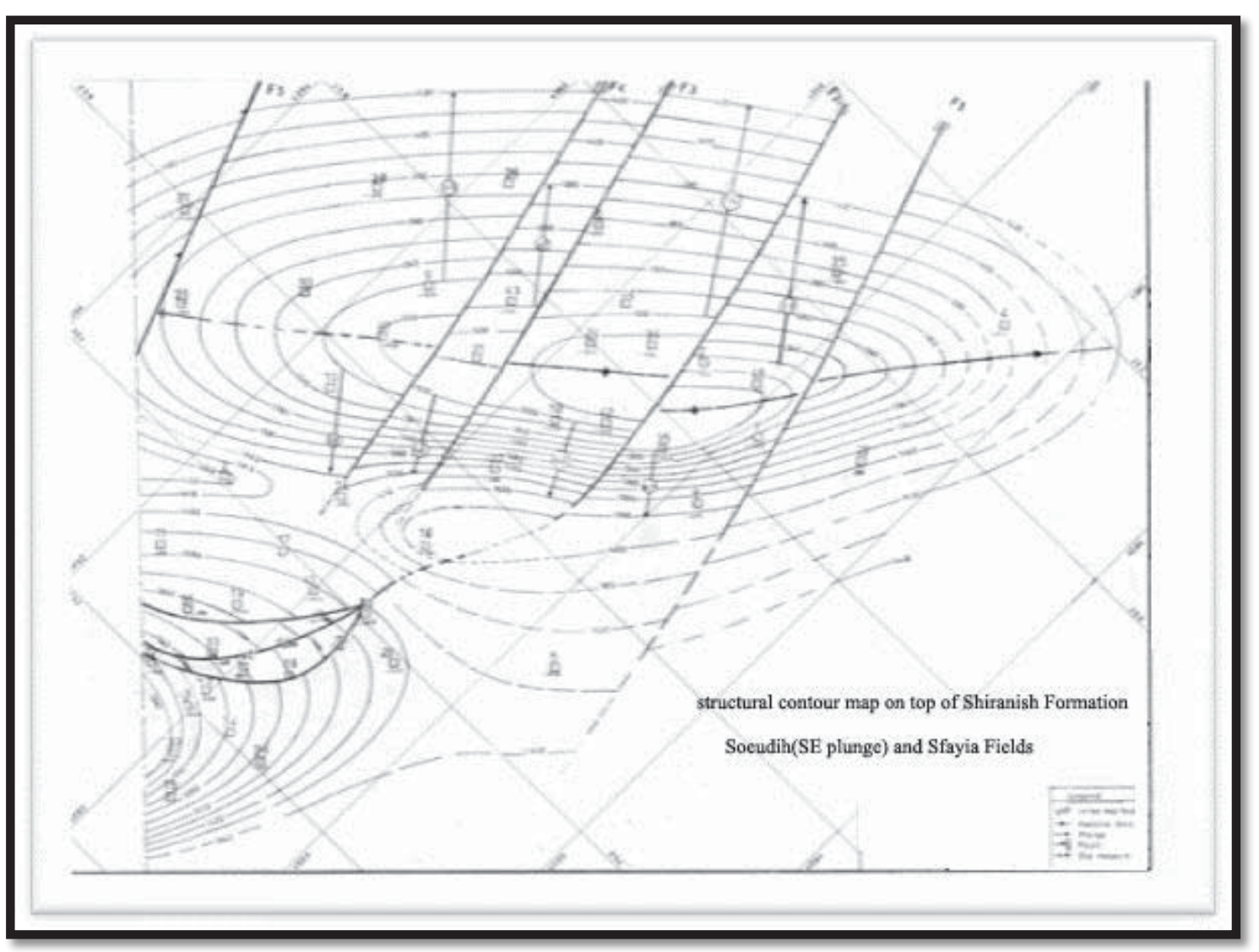

Fig. (4) Structure contour map on top of Gir Bir Formation

\section{Faults affecting on the structure contour map on top of Shiranish Formation:}

in depended on the structure contour map on top of Shiranish Formation, the Sfaiya area affected by five strike slip faults, and one normal fault, figure (3) as follows:

- The first strike slip fault (F1) left-hand (sinistral) movement, which is located between the Sf-1 and Sf-25 in the Sfaiya field, with a displacement of about 12 meters.

- The second strike slip fault (F2) right-hand (dextral)movement, which is located between the Sf-7 and Sf-35 in the Sfaiya field, which continues to cut the southeastern plunge of the Souedih Field, and is divided into a secondary strike slip faults, where is called flower strike slip faults, figure (5). 


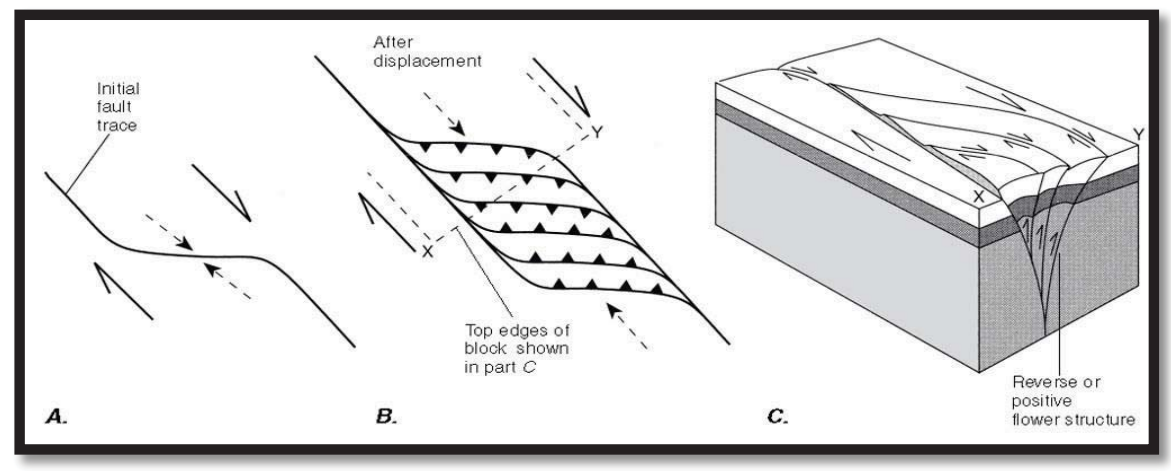

Fig. (5) Flower strike slip fault

- The third strike slip fault (F3) left-hand (sinistral) movement, which is located between Sf-44 and Sf-24 in the Sfaiya field, with a displacement of about 15 meters.

- The forth strike slip fault (F4) right-hand (dextral) movement, which is located between Sf-24 and Sf-6 in Sfaiya field, with a displacement of about 12 meters.

- The fifth strike slip fault (F5) left-hand (sinistral) movement, which is located between Sf-26 and Sf-9 in Sfaiya with a displacement of about 5 meters which end after the well of Sfaiya-18.

- The sixth normal fault (F6) is located in Sfaiya field near the Sf-37 and with a displacement of about 38 meters which may extend into the Syrian border.

\section{Faults affecting on the structure contour map on top of Gir Bir Formation}

in depended on the structure contour map on top of Gir Bir Formation, the Sfaiya area affected by four strike slip faults, and one normal fault, figure (4) as follows:

- The first strike slip fault (F1) left-hand (sinistral) movement, which is located between Sf-22 and Sf-25 in Sfaiya with a displacement of about 12 meters which end after the well of Sf-5.

- The second strike slip fault (F2) right-hand (dextral)movement, which is located between the Sf-7 and Sf-34 in the Sfaiya field, with displacement about 33 meters, which cut the southeastern plunge of the Souedih Field, and is divided into a secondary strike slip faults, where is called flower strike slip faults, figure (5).

- The third strike slip fault (F3) left-hand (sinistral) movement, which is located between Sf-43 and Sf-6 in Sfaiya with a displacement of about 5 meters, which end near the well of Sf-16. 
- The fourth strike slip fault (F4) right-hand (dextral)movement, which is located between the Sf-43 and Sf-26 in the Sfaiya field, with displacement about 5 meters, which ends near the well of Sf-18.

- The five normal faults (F5) are located in a Sfaiya field near the Sf-37 with displacement about 54 meters, which may extend into the Syrian border and may be cut the Swedish Field.

\section{Discussion the tectonic and structural situation of Sufaiya Field}

The current study show that the extension of the axis of Sufaiya structure is northwest southeast and differs from the surrounding structures, for example: Sinjar, Butmah and AinZalah structures, as the whole area surrounding the Sfaiya structure influenced by the Alpine movement (Turos), which is the extension of fold axis is East-West.

By observing the map confirmed by (Jassem and Goff, 2006), we divided Iraq to many blocks by Najed system faults and transversal system faults, as the study area is located to the upper hochuk-dohuk fault, according to (Jassim and Goff, 2006), and upper F1 according to the map of (Mohammed Shaker, 1993), figure (6).

The structural maps of the study area (the top of Shiranish and Gir Bir Formations) show that Sufaiya area was affected by a strike slip faults parallel and semi-parallel for main fault, which led to a change in the direction of the Sufaiya and Souedih Fields from east-west to northwestsoutheast, as well as, The push force of the Souedih Field to Sufaiya Field created a narrow syncline between them, which in turn helped to increase the deflection of the structure axis.

as the dip of the Sufaiya Field is small (a few degrees), and the displacement of strike slip faults have clearly led to the deviation of the Sfaiya axis to the northwest-southeast, direction of the Zagros, so that if the fold is returned to its initial position (canceled the displacement of strike slip faults) We will observe the direction of the structure axis to the east-west towards the Turos, and the expansion of the syncline between the Sufaiya and the Souedih Fields. 


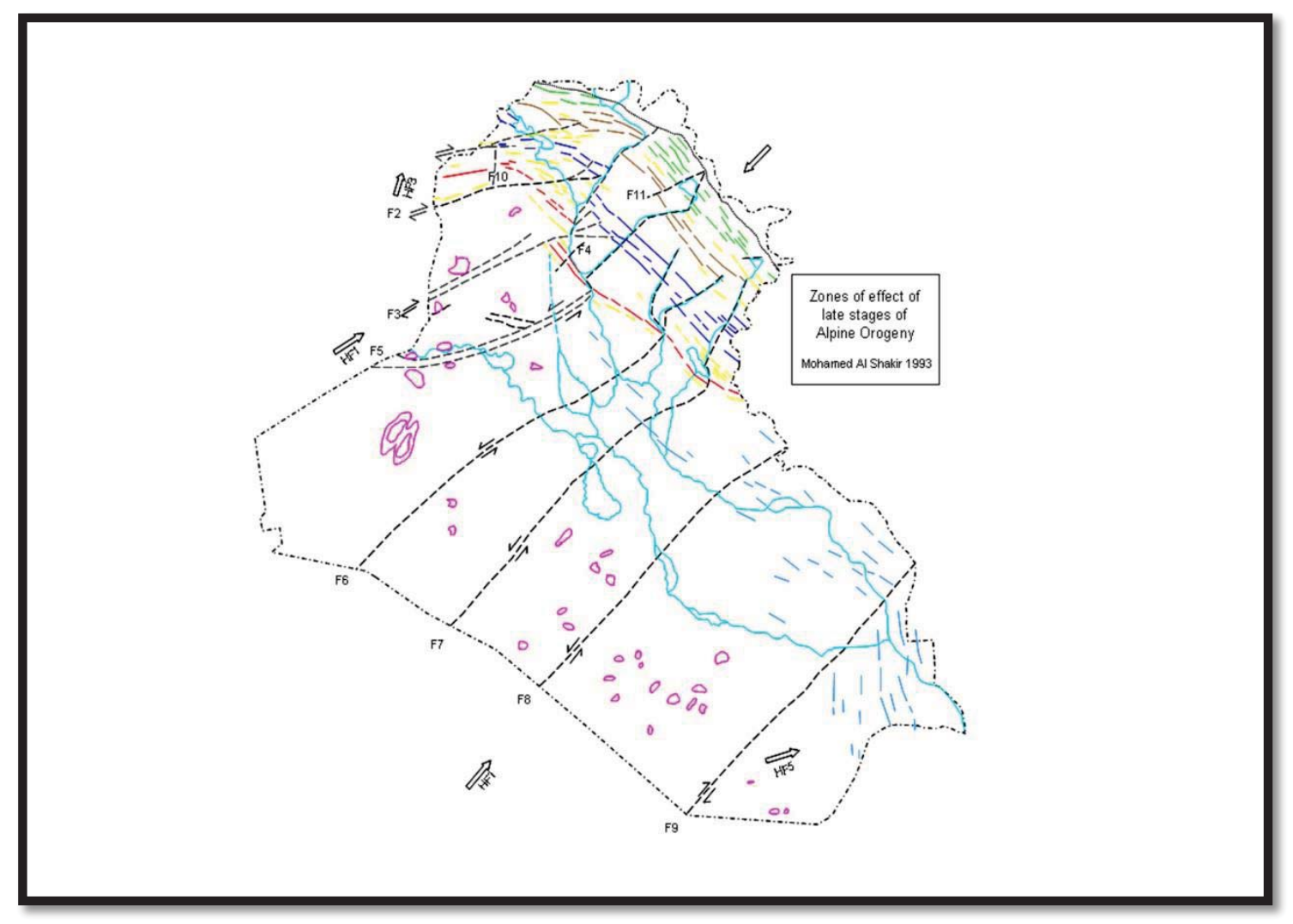

Fig. (6) illustrate the zone of effect of late Alpine Orogeny

Discussion the contacts of fluid levels in the Sufaiya Field and the southeastern plunge of the Souedih Field

The final reports of the drilled wells in the Sufaiya Field and the southeastern plunge of the Souedih Field, as well as, the results of the study of North Oil Company, 2010 were specified as follows:

- The lowest level of oil in a number of drilling wells because there is no clear level of contact of oil and water (OWC) in the Gir Bir reservoir because of the irregular and distribution of porosity, in the field of Sfaiya was determined at depth - 1466 meters below mean sea level, from sensors (log) and petrophysical analyzes in the well Sf29. This level was found in the well Sf-22 at the depth -1475 meters below mean sea level, and this is indicated by the results of the completion tests of the drilling wells.

- Oil and water contact (OWC) in the Gir Bir reservoir in Sf-4 at depth-1434 meters below mean sea level, and this level is similar to the other wells of Sfaiya field. 
- The level of oil and water contact (OWC) in the Gir Bir reservoir in the other wells near the Syrian border is at a depth -1375 meters below mean sea level, due to increased production from the Souedih Field.

As a result of the different levels of oil and water contact between the Souedih and Sufaiya structures and unconnected the values of top formations, it was separated the Souedih structure (southeastern plunge of the Souedih Field) from Sufaiya structure, then, Sufaiya structure containing 26 wells and the Souedih structure(southeastern plunge of the Souedih Field) contains 17 wells and the syncline Which separates the two structures contains 4 wells, it is preferable to rename the wells each according to its location of the structures.

\section{Conclusions:}

By updating the structural maps of the Sfaiya Field area, the following conclusions were reached:

1.The separation of the southeastern plunge of the Souedih Field from Sufaiya structure and the re-name of the wells (17 wells) in Souedih structure name, which located in this structure.

2. Determination flower strike slip fault cuts the Sfaiya structure and the southeastern plunge of the Souedih Field at the top of Shiranish and Gir Bir Formations.

3. The change in the direction of the Sufaiya axis from the direction of Turos to Zagros is due to displacement of strike slip faults, that affecting on the structures, in addition to the low dip of the flanks of the two structures. 


\section{References}

1. Al shaker, mohammed,1993: map of zone effect of Alpine orogeny. NOC Lib. Kirkuk.

2. Bulgarian Techno export Company,1977: Seismic survey for Sufaiya -Rabea, , unpublished study, geological library, Kirkuk.

3. EOC, 1980: Seismic survey for Sufaiya -Rabea and Sonono, unpublished study, geological library, Kirkuk.

4. Final wells reports, (47 wells). Wells Sufaiya, NOC Lib. Kirkuk.

5. Jassim, S. Z. and Goff, J. C.,2006: Geology OF IRAQ, Dolin, Prague and Moravian Museum, Brno.

6. NOC,2010: (in arabic) Geological and petrophisical study for Cretaceous reservoir in Sufaiya Field-NW Iraq, unpublished study, geological library, Kirkuk.

7. Sherland P., Archer R., Casey D., Davies R., Hall, Heward A., Horbury A., Simmon M., 2001: Arabian plate sequencese stratigraphy. 371p. Geo Arab. sp. 